\title{
In Memory of RNDr Václav Šašek, CSc (1937-2019)
}

\author{
Jiří Gabriela \& Ivan Jablonskýb,*

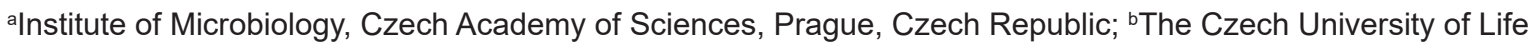 \\ Sciences, Prague, Czech Republic \\ *Address all correspondence to: Ivan Jablonský, The Czech University of Life Sciences, Kamýcká 129, 16500 Praha 6 - Suchdo, Czech Republic, \\ E-mail: I.Jablonsky@seznam.cz
}

RNDr Václav Šašek, aged 82 years, passed away on January 10, 2019. He stood at the birth of Czech experimental mycology and became involved in many parts of the field.

Dr. Šašek was born on February 6, 1937, in Prague in former Czechoslovakia. He studied plant biology at Charles University's Faculty of Science there. His interest in mycology began in connection with his thesis, "Roses, with Special Regard to Rosa and Their Mycoflora." This was his first serious contact with mycology. After graduating with a degree in biology and chemistry in 1960, he spent 2 years teaching biology and chemistry to high school students. In 1961 he joined the doctoral degree program at the Biological Institutes of the Czech Academy of Sciences.

In 1966, Dr. Šašek was awarded a CSc degree after defending his thesis, "Cultivation and Antibiotic Activity of Mycorrhizal Fungi." He proved that, in addition to the trophic significance of mycorrhizal fungus-host plant interactions, fungi play a protective role in antibiotic production. Beginning in 1968, he spent 1 year at the University of Iowa in the

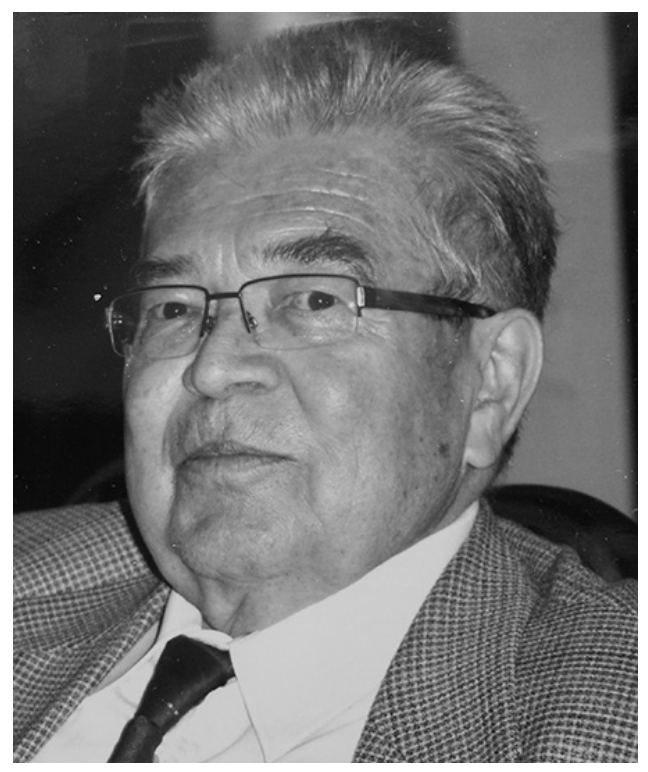

Václav Šašek United States.

Fungal antibiotics had been a new topic of his work at the Institute of Microbiology at the Czechoslovak Academy of Sciences. Dr. Vladimír Musílek's mycology group, which Dr. Šašek joined, focused on studying the production of antibiotics by higher fungi. Dr. Šašek's work included isolating, cultivating, and studying the nutrition, growth, and biochemical properties of fungal isolates. Dr. Šašek described the morphological changes that mucin induced in yeast and filamentous fungi. He also participated in the work of the patent team at the institute of microbiology to protect new antibiotics. A new antifungal antibiotic was isolated from the Oudemansiella mucida mushroom, and it achieved clinical application and was manufactured under the trade name Mucidermin Spofa. However, the authorities did not provide patent protection for the antibiotic mucidermin spofa, so scientists in Germany were able to patent a substance with the same properties (strobilurin A), isolated from the Strobilurus tenacellus mushroom. Today, that substance is among the most used fungicides in agriculture.

Later, Dr. Šašek studied the physiological and biochemical properties of Pyrenomycetes; participated in the discovery of a new flavivirin antibiotic produced by Melanconis flavovirens; and, as the author of 5 books and coauthor of the Encyclopedia of Gardening, contributed to expanding knowledge about the cultivation of various types of edible and medicinal mushrooms.

Dr. Šašek was interested in other biological activities of higher fungi, especially medicinally active ones. During his stay in the Soviet Union in 1966 and 1976, he met renowned mycologists such as Prof. Jakimov and Dr. A.N. Šivrina, who studied biologically active fungi and inspired him to perform fur- 
ther experimental work. He also repeatedly visited the M.G. Kholodny Institute of Botany at the National Academy of Sciences of Ukraine in Kiev, cooperating with professors A.S. Buchalo and S.P. Wasser. From the early 1990s, Dr. Šašek led the Laboratory of Experimental Mycology, and until 1999 he was the head of the Institute of Microbiology of the Czech Academy of Sciences (IM CAS) Ecology Sector. His work during this period focused on research on ligninolytic Basidiomycetes and their applications in remediating soil contamination from persistent organopollutants such as polycyclic aromatic hydrocarbons and polychlorinated biphenyls. His previous experience in the field of physiology and biochemistry of ligninolytic fungi was thus linked to ecologically oriented soil biology research concentrating on the mechanisms by which ligninolytic fungi decompose recalcitrant aromatic organopollutants. This research was developed in the frame of several Czech projects supported by the Czech Science Foundation and the Ministry of Education, Youth and Sports of the Czech Republic during the period 1994 to 2000. In parallel, bilateral cooperation was established with foreign universities and institutes - namely, the laboratory of Professor H.-P. Molitoris at the University of Regensburg, Germany, and the laboratory of Professor C.G. Dosoretz in the MIGAL Galilee Research Institute in Kiryat Shmona, Israel. Dr. Šašek also participated in broader cooperation with other laboratories in Europe, such as Georg August University, Göttingen, Germany; IFA Tulln, University of Natural Resources and Life Sciences, Vienna, Austria; CERMAV-CNRS, University Grenoble Alpes, Grenoble, France; and Tuscia University, Viterbo, Italy. The period of research focused on remediating organopollutants through cooperation with foreign institutes and universities. Dr. Šašek closed out this period by organizing an international NATO Advanced Research Workshop, titled "The Utilization of Bioremediation to Reduce Soil Contamination: Problems and Solutions," at Liblice, Czech Republic, in 2000. His international research and cooperation also included pedagogical activities - namely, tutoring several $\mathrm{PhD}$ students from India and Italy who worked in his laboratory in Prague while they wrote their theses. During his professional career he published 260 scientific publications, including original papers, abstracts, and book chapters.

Last but not least, Dr. Šašek also established cooperation with the Institute of Chemical Technology in Prague, through which he investigated the ability of ligninolytic fungi to deteriorate polyesteramides and aliphatic-aromatic copolyesters. The Laboratory of Experimental Mycology continued this cooperation even after Dr. Šašek retired.

Dr. Šašek's teaching and organizational activity was very broad. From the 1970s he lectured about the physiology of mushrooms at the Faculty of Science of Charles University in Prague, where he advised a number of PhD students and foreign UNESCO trainees. The Czech Society for Mycology, where he had worked as chairman of the Experimental Mycology Commission since 1978, granted him a lifetime membership. He was a member of many scientific societies and in 2007 was awarded Patočka's Medal, the highest prize from the Czechoslovak Society for Microbiology, for his activities as the head of its mycological section.

Dr. Šašek retired after 47 years of intense work at the Institute of Microbiology of the Czech Academy of Sciences. The research group he established has continued investigating biodegradation processes on a broader scale, focusing on various endocrine-disrupting compounds.

Dr. Šašek was an expert reviewer for the International Journal of Medicinal Mushrooms, Czech Mycology, Folia Microbiologica, and many other scientific journals. For 10 years he was a member of the editorial board of the International Journal of Medicinal Mushrooms. He was a diligent and creative reviewer, and he wrote many important papers. Dr. Šašek took part in many of the International Medicinal Mushrooms Conferences since the first one held in 2001 in Kiev. He helped to organize the first through fifth of these conferences.

In his youth, Dr. Šašek was a passionate cyclist, going for many long trips. He also had an excellent musical ear and was an expert in classical opera. The Czech Republic and the scientific community worldwide have lost a great human being, a scientist, and, for many of us, a loyal friend. All his friends and colleagues regret losing his vast knowledge, brisk mind, and kind heart. 